\title{
Vasopressin at Central Levels and Consequences of Dehydration
}

\author{
Daniel G. Bichet \\ Department of Medicine and Molecular and Integrative Physiology, University of Montreal, and Service de \\ Néphrologie, Montreal, Que., Canada
}

\author{
Key Words \\ Vasopressin · Dehydration · TRPV1 · TRPV4 · Thirst
}

\begin{abstract}
Disorders of water balance are a common feature of clinical practice. An understanding of the physiology and pathophysiology of central vasopressin release and perception of thirst is the key to diagnosis and management of these disorders. Mammals are osmoregulators; they have evolved mechanisms that maintain extracellular fluid osmolality near a stable value, and, in animal studies, osmoregulatory neurons express a truncated delta-N variant of the transient receptor potential vannilloid (TRPV1) channel involved in hypertonicity and thermal perception while systemic hypotonicity might be perceived by TRPV4 channels. Recent cellular and optogenetic animal experiments demonstrate that, in addition to the multifactorial process of excretion, circumventricular organ sensors reacting to osmotic pressure and angiotensin II, subserve genesis of thirst, volume regulation and behavioral effects of thirst avoidance. $\quad$ ○ 2016 The Author(s)

Published by S. Karger AG, Basel
\end{abstract}

\section{Structure of the Neurohypophysis: Anatomy and Function of Vasopressin-Producing Cells}

The hypothalamus, a small, one cubic centimeter structure in humans, is located at the anterior and ventral part of the thalamus, and embodies a group of nuclei that

\section{KARGER}

E-Mail karger@karger.com www.karger.com/anm

\section{(C) 2016 The Author(s) \\ Published by S. Karger AG, Basel $0250-6807 / 16 / 0686-0019 \$ 39.50 / 0$}

This article is licensed under the Creative Commons AttributionNonCommercial-NoDerivatives 4.0 International License (CC BYNC-ND) (http://www.karger.com/Services/OpenAccessLicense). Usage and distribution for commercial purposes as well as any distribution of modified material requires written permission. form the floor and ventrolateral walls of the triangularshaped third ventricle [1]. The neurohypophysis consists of (1) a set of hypothalamic nuclei, namely the supraoptic nuclei (SON) and paraventricular nuclei (PVN), which house the perikarya of the magnocellular neurons; (2) axonal processes of the magnocellular neurons form the supraoptical hypophyseal tract; and (3) the secretory material of these neurons, which is transported to the posterior pituitary (PP) gland (fig. 1). Large neurosecretory magnocellular cells of 20-40 $\mu \mathrm{m}$ and smaller parvocellular cells of 10-15 $\mu \mathrm{m}$ are neuroendocrine, autonomic and circadian controllers and regulators. Oxytocin and arginine vasopressin (AVP) are synthesized in different populations of magnocellular neurons from the supraoptic, paraventricular and accessory nuclei [2]. Evolutionary theory suggests that secretion of these peptides in the cerebrospinal fluid has been replaced by a vascular secretion. In advanced vertebrates, the axonal projections of these neurons are toward the PP and also to forebrain, telencephalon and diencephalon regions, probably explaining the behavioral effects of oxytocin [3] and vasopressin (VP) [2].

Tonicity is perceived specifically by neuronal groups on the anterior wall of the third cerebral ventricle (fig. 1). All cells of an organism respond to dehydration or to hyperhydration by changing volume, but cells of the subfornical organ (SFO), organum vasculosum of the lamina terminalis (OVLT), median preoptic nucleus (MnPO) are 'perfect' osmoreceptors, that is, their changes in volume are maintained as long as the osmotic stimulus 


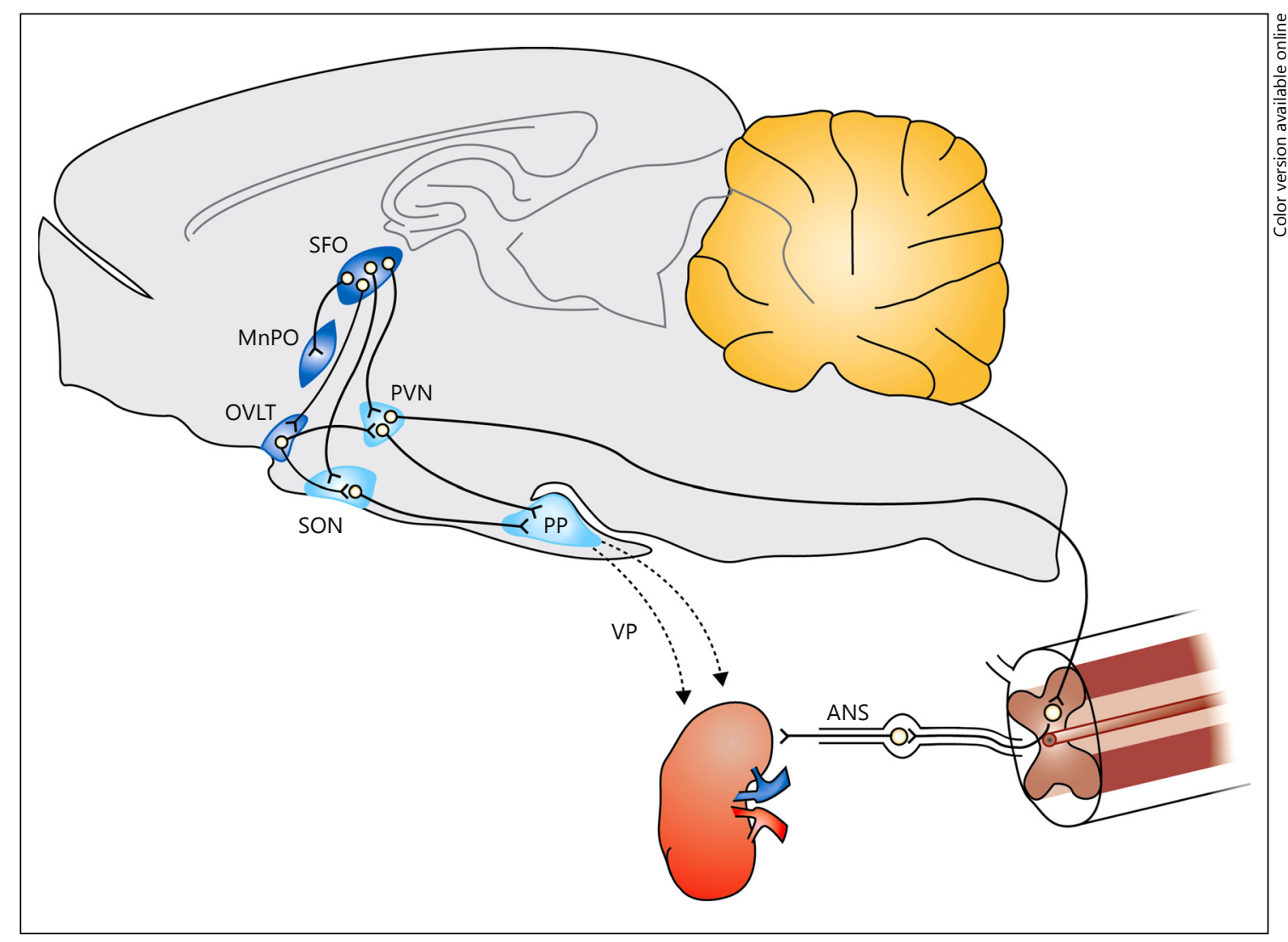

Fig. 1. Schematic representation of the osmoregulatory pathway of the hypothalamus (sagittal section of midline of ventral brain around the third ventricle in mice). Neurons (lightly filled circles) in the OVLT, MnPO and SFO, that are responsive to plasma hypertonicity, send efferent axonal projections (black lines) to magnocellular neurons of the PVN and SON. The axons of these magnocellular neurons form the hypothalamo-neurohypophyseal

persists [4]. Cell shrinking during dehydration is mechanically coupled to the activation of delta- $\mathrm{N}$ transient receptor potential vannilloid (TRPV1) channels [5], a molecular co-detector of body temperature and osmotic stress, through a densely interweaved microtubule network present only in osmosensitive cells [4], including excitatory thirst neurons from the SFO [6] (fig. 2).

These excitatory SFO neurons project to magnocellular cells of the SON and PVN, producing VP. These neurosecretory cells are depolarized and VP is released both from axonal and dendritic terminals. Dendritic VP release during dehydration stimulates sympathetic pre-autonomic cells in the PVN and directly increases renal nerve stimulation, a central integrated response to restore tonicity and volume [7] (fig. 1). VP-producing cells in SON and PVN also bear delta-N TRPV1 channels, which depolarize during dehydration and hyperpolarize during pathway that courses in the median eminence to reach the PP, where neurosecretion of VP and oxytocin occurs. Dendritic VP release during dehydration stimulates sympathetic pre-autonomic cells in the PVN and directly increases renal autonomic nerve stimulation (ANS) [7], a central integrated response to restore tonicity and volume. Modified from [11] with permission.

overhydration. VP release is the net result of this depolarization (fig. 3).

Thirst cells of the anterior wall of the third ventricle also project to 2 conscious areas - the anterior cingulate cortex and the insula - delivering a conscious assessment of the dehydration state and, probably, the necessary water volume to quench thirst [8]. This is a unique situation where tonicity is consciously perceived, analogous to hunger perception. Like hunger promoting neurons, thirst promoting neurons transmit negative valence teaching signals that are actively avoided by experimental animals [9]. In experimental animals, elevated drinking was observed by optogenetically activating a SFO neuronal subpopulation that had been defined by expression of nitric oxide synthase 1 (NOS1). SFO ${ }^{\text {NOS1-ChR2 }}$ photostimulation rapidly increased water consumption, but not food intake. To examine the conditioning properties of 


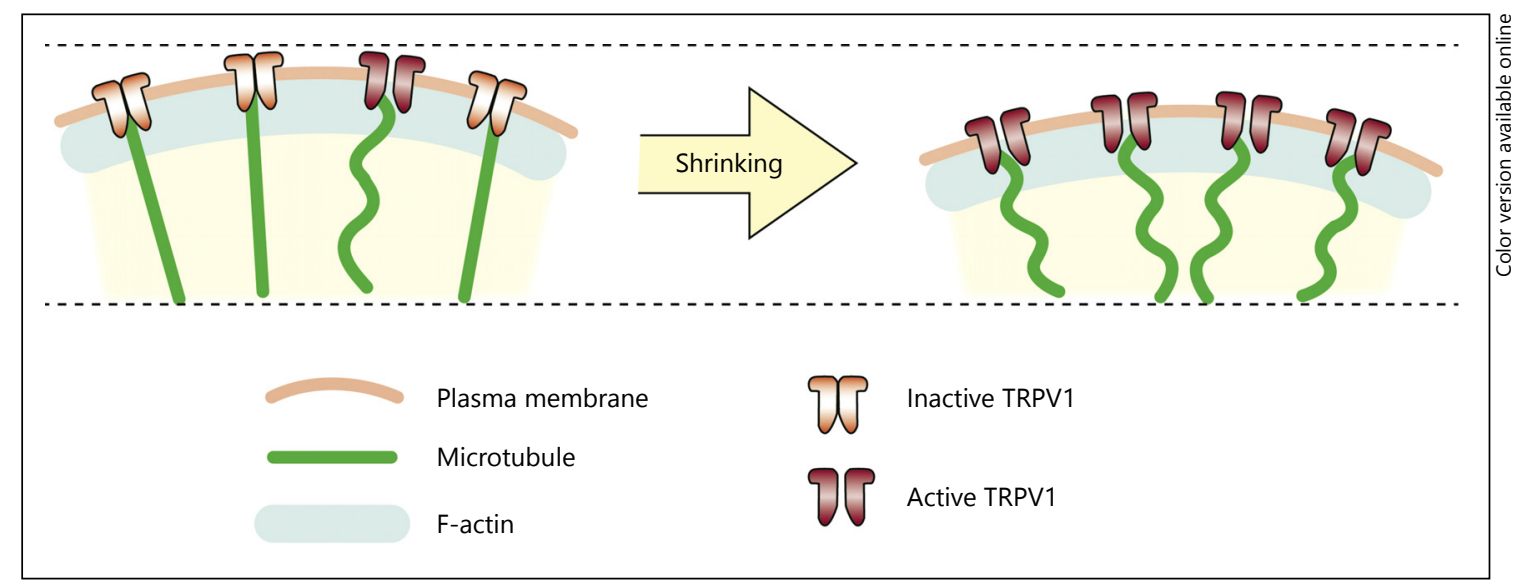

Fig. 2. Cell shrinking of hypothalamic osmoreceptor cells during dehydration is mechanically coupled to activation of delta-N TRPV1 channels. As a result of cell shrinking, the plasma membrane shifts inward (right), increasing the proportion of microtubules that push onto (and activate) delta-N TRPV1 channels [4]. This will depolarize osmoreceptor cells and stimulate thirst and vasopressin release (fig. 3).

SFO $^{\text {NOS1 }}$ neurons, a double chambered apparatus was used with visual and textural cues, and mice showed avoidance of the side paired with $\mathrm{SFO}^{\mathrm{NOS} 1}$ neuron photostimulation; thus, a virtual thirst state was clearly avoided in these experiments [9]. The precise neuronal circuits linking thirst to negative valence signals could possibly involve limbic projections from thirst or VP neurons [2]. The net effect may be to condition animals to have a preference for cues associated with food intake.

The OVLT, SFO, MnPO and the pituitary gland do not have a blood-brain barrier; their capillary endothelium is fenestrated and allows full exposure to plasma osmotic and hormonal variations including angiotensin II. Excitatory thirst neurons of the SFO specifically expressed AT1 angiotensin receptors [6], probably explaining the osmoregulatory gain observed with increased circulating plasma levels of angiotensin [10]. This osmoregulatory gain is clinically important since, for the same osmotic stimulus, more VP is released when plasma angiotensin II is elevated. This situation is commonly seen with hypotension, a decreased effective blood volume of heart failure and decompensated cirrhosis, where hyponatremia with high VP levels are often observed.

The SON lies dorsal to the optic chiasm and approximately $2 \mathrm{~mm}$ from the third ventricle. The PVN lies closer to the thalamus in the suprachiasmatic portion of the hypothalamus, but it borders on the third ventricular space. These well-defined nuclei contain the majority of the large neuroendocrine cell bodies, known as the 100,000 magnocellular or neurosecretory cells, that manufacture AVP and oxytocin [11, 12]. Axons and axonal collaterals project not only to the PP but also to the forebrain and limbic areas [2]. Dendritic release of VP, of considerable importance during dehydration to induce a central pre-autonomic stimulation [7], leads to extremely high local brain concentrations of VP $[12,13]$. Parvocellular pre-autonomic neurons of PVN send long descending projections to sympathetic and parasympathetic centers in the brain stem and spinal cord, modulating sympathetic and parasympathetic outflows to a variety of target organs, including the heart, the peripheral vasculature and the kidneys. In addition to neurosecretory and autonomic targets, PVNs also include neurons that project to higher centers in the brain, including the central amygdala, projections recently shown to modulate fearconditioned responses [13]. PVN also receive afferents from the nucleus solitarius and other spinal cardiovascular regulatory afferents, thereby coordinating sympathetic, parasympathetic and somatomotor information to the endocrine activity.

Finally, immunohistochemical studies have revealed a second VP neurosecretory pathway that transports high concentrations of the hormone to the anterior pituitary gland (i.e., from parvocellular neurons to the hypophyseal portal system). In the portal system, the high concentration of AVP acts synergistically with corticotropin-releasing hormone $(\mathrm{CRH})$ to stimulate adrenocorticotropin (ACTH) release from the anterior pituitary. More than half of the parvocellular neurons co-express both $\mathrm{CRH}$ and AVP. In addition, while passing through the median eminence and the hypophyseal stalk, magnocellular axons can also release AVP into the long portal sys- 


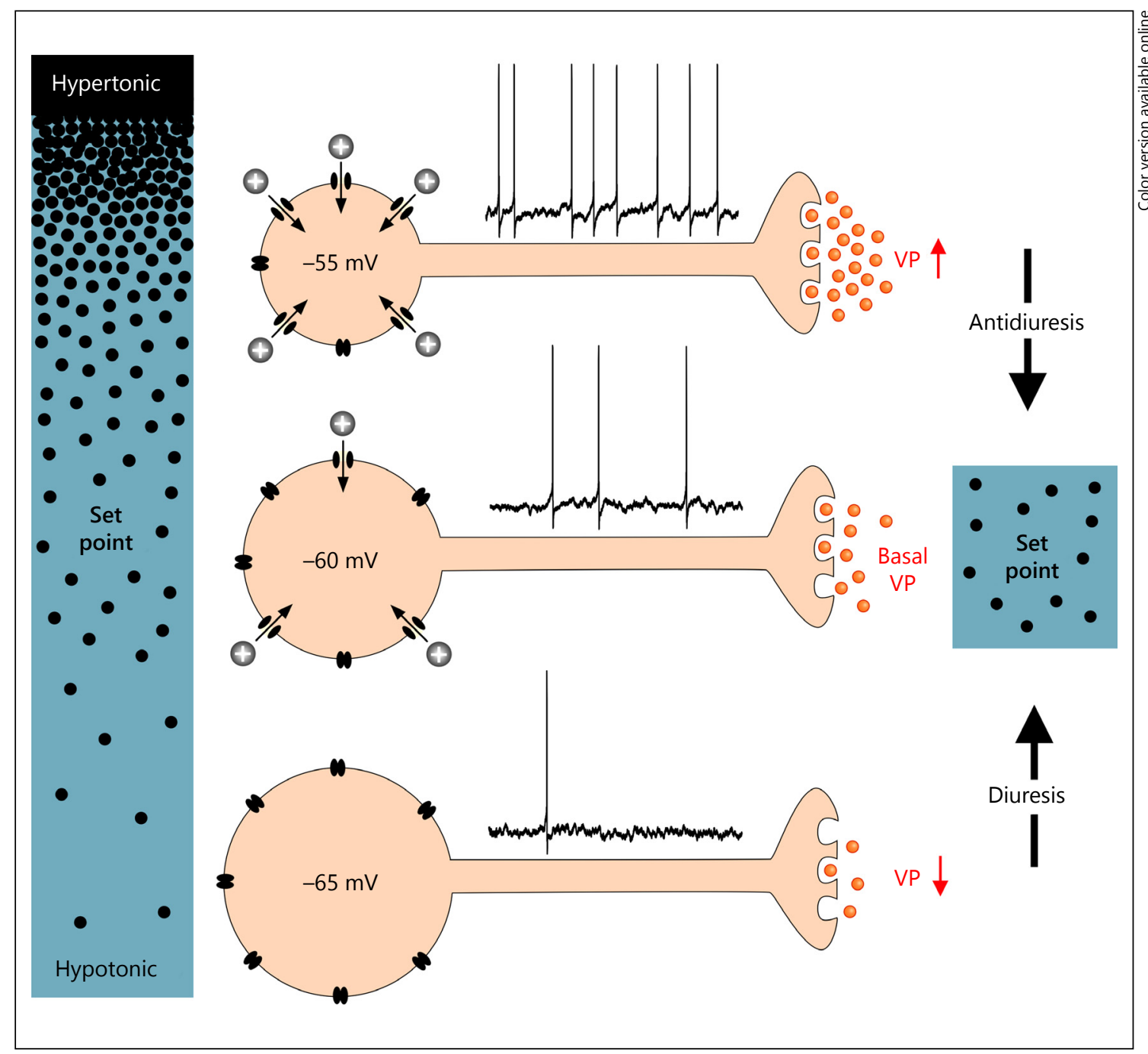

Fig. 3. Cell autonomous osmoreception in VP neurons. Changes in extracellular osmolality cause inversely proportional changes in soma volume. This shrinkage activates delta-N TRPV1 channels, and the ensuing depolarization increases action potential firing rate and VP release from axon terminals in the neurohypophysis.

tem. Furthermore, a number of neuroanatomical studies have shown the existence of short portal vessels that allow communication between the posterior and anterior pituitary. Thus, in addition to parvocellular VP, magnocellular VP is able to influence ACTH secretion $[14,15]$.

\section{Summary}

The osmoregulatory mechanisms described here in experimental animals are also well described in humans after strenuous exercise, water deprivation and water
Increased VP levels in blood enhance water reabsorption in the kidney (anti-diuresis), to restore extracellular fluid osmolality toward the set point. Hypotonic stimuli inhibit TRPV1. The resulting hyperpolarization and inhibition of neuronal firing reduces VP release and promotes diuresis. Modified from [4].

absorption [8]. Recent optogenetic experiments in mice have deciphered the anatomical and molecular components of thirst and hunger and their behavioral components $[6,9]$. New blood-oxygen-level-dependent human studies could possibly confirm these basic advances [8].

\section{Disclosure Statement}

The author declares that no financial or other conflict of interest exists in relation to the contents of the above paper. 


\section{References}

1 Martin JH: The Hypothalamus and Regulation of Bodily Functions; in Martin JH (ed): Neuroanatomy Text and Atlas, ed 4. McGraw Hill, 2012, pp 355-383.

2 Knobloch HS, Grinevich V: Evolution of oxytocin pathways in the brain of vertebrates. Front Behav Neurosci 2014;8:31.

3 Burkett JP, Andari E, Johnson ZV, Curry DC, de Waal FB, Young LJ: Oxytocin-dependent consolation behavior in rodents. Science 2016;351:375-378.

4 Prager-Khoutorsky M, Bourque CW: Mechanical basis of osmosensory transduction in magnocellular neurosecretory neurones of the rat supraoptic nucleus. J Neuroendocrinol 2015;27:507-515.

5 Zaelzer C, Hua P, Prager-Khoutorsky M, et al: $\triangle$ N-TRPV1: a molecular co-detector of body temperature and osmotic stress. Cell Rep 2015;13:23-30.
6 Oka Y, Ye M, Zuker CS: Thirst driving and suppressing signals encoded by distinct neural populations in the brain. Nature 2015;520: 349-352.

7 Son SJ, Filosa JA, Potapenko ES, et al: Dendritic peptide release mediates interpopulation crosstalk between neurosecretory and preautonomic networks. Neuron 2013;78: 1036-1049.

8 Bourque CW: Central mechanisms of osmosensation and systemic osmoregulation. Nat Rev Neurosci 2008;9:519-531.

9 Betley JN, Xu S, Cao ZF, et al: Neurons for hunger and thirst transmit a negative-valence teaching signal. Nature 2015;521:180-185.

10 Zhang Z, Bourque CW: Amplification of transducer gain by angiotensin II-mediated enhancement of cortical actin density in osmosensory neurons. J Neurosci 2008;28: 9536-9544.

11 Wilson Y, Nag N, Davern P, et al: Visualization of functionally activated circuitry in the brain. Proc Natl Acad Sci U S A 2002;99:32523257.
12 Ludwig M, Leng G: Dendritic peptide release and peptide-dependent behaviours. Nat Rev Neurosci 2006;7:126-136.

13 Ludwig M, Stern J: Multiple signalling modalities mediated by dendritic exocytosis of oxytocin and vasopressin. Philos Trans R Soc Lond B Biol Sci 2015;370:pii:20140182.

14 Kalogeras KT, Nieman LK, Friedman TC, et al: Inferior petrosal sinus sampling in healthy subjects reveals a unilateral corticotropin-releasing hormone-induced arginine vasopressin release associated with ipsilateral adrenocorticotropin secretion. J Clin Invest 1996;97: 2045-2050.

15 Yanovski JA, Friedman TC, Nieman LK, et al: Inferior petrosal sinus AVP in patients with Cushing's syndrome. Clin Endocrinol (Oxf) 1997;47:199-206. 